\title{
Avaliação do tempo de prateleira (shelf time) de aromatizantes de ambiente por espectroscopia de raios- $X$ aliada à quimiometria.
}

\author{
Maria Izabel M. S. Bueno (PQ), Natasha F. Afonso (IC).
}

\section{Resumo}

Métodos rápidos e verdes têm sido desenvolvidos na área da química a cada dia com maior ênfase, sempre com o intuito de se trabalhar sem agredir o meio-ambiente. Neste sentido, este projeto estabeleceu a cinética da perda de fragrância de aromatizantes de ambiente, aliando-se Fluorescência de Raios- $X$ com Análise de Componentes Principais (mais conhecido como PCA, Principal Component Analysis). Foi possível estabelecer o tempo de prateleira (shelf time) desta amostra, que foi escolhida por ser fácil de ser trabalhada usando a técnica analítica pretendida, como também ter em seu rótulo o prazo de validade, que foi confrontado com os resultados obtidos.

Palavras Chave: Shelf time, Raios-x, Aromatizantes.

\section{Introdução}

O desenvolvimento e controle de qualidade de aromatizantes de ambiente é feita essencialmente por análise sensorial, porém esse estudo propõem o uso da fluorescência de raios- $X$ aliada a quimiometria como um método alternativo para o controle de qualidade desses produtos. A fluorescência de raios- $X$ tradicional é baseada no efeito fotoelétrico, que, em resumo, é a liberação de um elétron pela ação de um fóton. ${ }^{(1)}$.

A espectroscopia de raios- $X$ é um método vantajoso principalmente por ser rápido e verde, não sendo necessária a preparação da amostra e não gerando resíduos.

\section{Resultados e Discussão}

As amostras de 2 a 6 e 8, foram simplesmente abertas e colocadas no ambiente; a amostra 7 foi ligada no aparelho na tomada; e a amostra 9 foi deixada no suporte de vidro. As amostras foram analisadas sequencialmente (amostra 2, em seguida amostra 3 e assim por diante) com um intervalo aproximado de 30 minutos entre as análises de uma mesma amostra no mesmo dia.

Figura 1. Fotos de como os refis ficaram no ambiente durante os 56 dias de experimento.

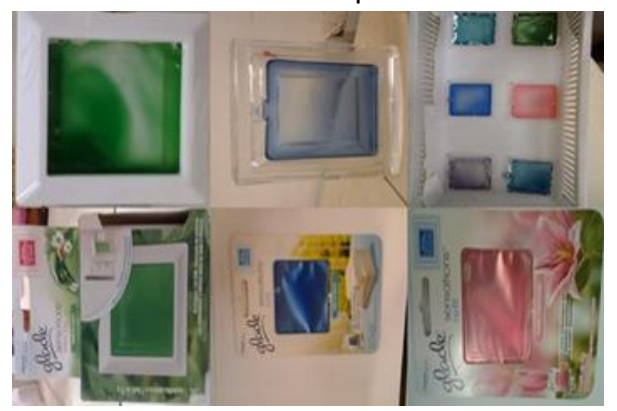

Figura 2. Gráfico da PC1 de cada amostra pelo tempo, em dias, que a amostra estava no ambiente.

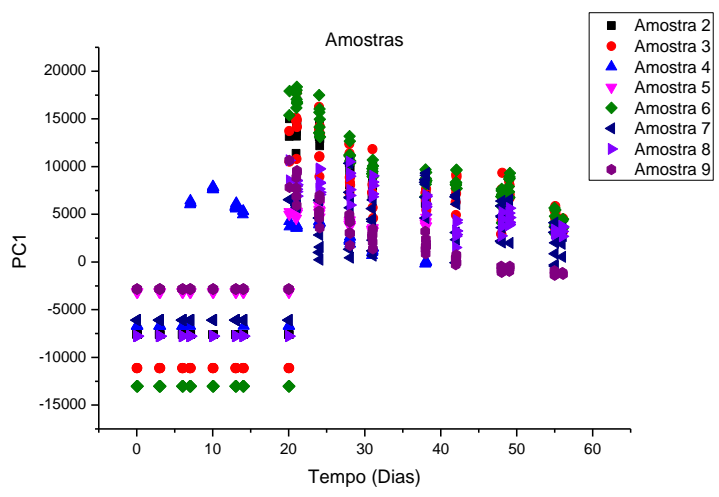

\section{Conclusões}

A fluorescência de raios- $X$ associada a quimiometria permitiu determinar que após 20 dias no ambiente as amostras apresentaram uma mudança abrupta nos valores da PC1. Além da perda d'água e da perda de fragrância, poderia estar ocorrendo a cristalização da amostra, o que sugere que todas as amostras contém o mesmo gel em sua composição, porém outras técnicas analíticas devem ser usadas para evidenciar estas ocorrências.

\section{Agradecimentos}

Agradecimento à professora doutora Maria Izabel M. S. Bueno pela ajuda, dedicação e paciência durante todo o período.

Bolsa de iniciação científica PIBIC.

\footnotetext{
${ }^{1}$ JENKINS, R. X-Ray Fluorescence Spectrometry. $2^{\mathrm{a}}$ edição. New York: John Wiley \& Sons, 1999.
} 